\title{
Subacute thyroiditis associated with Chlamydia Psittaci infection
}

\author{
P.M. Schofield and E.E. Keal \\ St. Mary's Hospital, Praed Street, London W2 1NY, UK.
}

\begin{abstract}
Summary: A patient presenting with subacute thyroiditis who had evidence of chlamydial infection is reported.
\end{abstract}

\section{Introduction}

Subacute thyroiditis is generally believed to be of viral origin and several viruses have been implicated in its aetiology (Levine, 1983). A search of the world literature over the past 20 years did not reveal any previously reported cases associated with chlamydial infection.

\section{Case report}

A 33 year old female presented in January 1984 with a month's history of swelling in the neck. For 3 weeks, the swelling had been painful and she had some difficulty with swallowing. At the onset of her illness she was pyrexial, had 'flu-like' symptoms and also complained of anorexia and loss of $4 \mathrm{~kg}$ in weight. On examination she had a diffusely enlarged and very tender thyroid gland. She was clinically euthyroid and examination was otherwise normal. Initial investigations revealed haemoglobin $11.6 \mathrm{~g} / \mathrm{dl}$, white cell count $7.5 \times 10^{9} / 1$, erythrocyte sedimentation rate $35 \mathrm{~mm}$ in 1 hour, aspartate transaminase $57 \mathrm{U} / 1$ (normal range 7-40), alkaline phosphatase $167 \mathrm{U} / 1$ (normal 30-130), thyroxine $185 \mathrm{nmol} / 1$ (normal 50-150), free thyroxine index 195 (normal 45-160), free thyroxine $31 \mathrm{pmol} / 1$ (normal 8.8-23) and a ${ }^{123}$ I thyroid scan showed very poor thyroid uptake (at $20 \mathrm{~min} 3 \%$ and at $2 \mathrm{~h} 2 \%$ ). She was treated with aspirin for 7 days without response and subsequently thyroxine $0.2 \mathrm{mg} / \mathrm{day}$ was substituted.

Within 3 days of starting thyroxine therapy the gland was no longer painful: the dosage was later reduced and treatment continued for 1 month. Six

Correspondence: P.M. Schofield M.R.C.P.

Accepted: 6 February 1985 weeks after her initial presentation she felt completely well, although her thyroid gland remained enlarged. Within 3 months, the thyroid was no longer enlarged. Both thyroglobulin and microsomal antibodies were negative. Repeat aspartate transaminase and alkaline phosphatase levels were normal. Serum thyroxine returned to normal within 6 weeks and has remained normal.

At her initial presentation the Chlamydia complement fixation test, performed as part of a routine screen, was positive at $1 / 640$ (4 January 1984). The titre has since fallen to $1 / 320$ (17 February 1984) and subsequently 1/20 (31 May 1984). Viral antibody titres were not raised. A repeat thyroid scan 5 months after presentation was normal. She had no chest symptoms, had a normal chest radiograph and gave no history of contact with birds.

\section{Discussion}

Subacute thyroiditis is an inflammatory disorder characterized pathologically by the presence of giant cells and granulomas. The condition is generally believed to be of viral origin. Increases in viral antibody titres are noted in a substantial number of patients, and occasionally viruses have been cultured from affected tissue. The viruses most frequently implicated include mumps, measles, influenza, Epstein-Barr, Coxsackie and adenovirus (Levine, 1983). Subacute thyroiditis has also been described in a patient with Q fever by Greene (1971).

The clinical presentation of psittacosis can vary widely from a mild 'flu-like' illness to a fulminating toxic state with multiple organ involvement. In man, the lung is the organ most consistently involved with 
Chlamydia psittaci infections. However, a variety of extrapulmonary complications have been described by Macfarlane \& Macrae (1983) and Murray \& Tuazon (1980). These include endocarditis, myocarditis and pericarditis. In addition to acute confusion, encephalitis and meningitis have also been reported. Gastrointestinal manifestations, for example hepatomegaly, splenomegaly, hepatitis and pancreatitis, may occur. Both Macfarlane \& Macrae (1983) and Murray \& Tuazon (1980) mention thyroiditis as a possible extrapulmonary feature. However, they refer to a series of 13 patients with psittacosis reported by Seibert et al. (1956). In this series, one patient had transient tenderness of the isthmus of the thyroid gland. Although this was attributed to acute thyroiditis, thyroid function tests and thyroid scan were not performed.

The diagnosis of psittacosis, which is almost exclusively serological, has been receiving attention recently (Isaacs, 1984; Editorial, 1984). The Chlamydia complement fixation test, which detects group antibody, does not distinguish between $C$. psittaci and C. trachomatis. However, Isaacs (1984) suggests that the clinical syndromes are usually dis-

\section{References}

EDITORIAL (1984). Psittacosis of non-avian origin. Lancet, ii, 442.

GREENE, J.N. (1971). Subacute thyroiditis. American Journal of Medicine, 51, 97.

ISAACS, D. (1984). Psittacosis. British Medical Journal, 289, 510.

LEVINE, S.N. (1983). Current concepts of thyroiditis. Archives of Internal Medicine, 143, 1952. similar enough for this to be a minor problem. Ouf patient had no eye or genitourinary symptoms and the prodromal illness was consistent with the milder form of psittacosis. Although we were unable to document 9 fourfold rise in antibody titre, due to symptoms being present for 4 weeks before presentation, the initiat antibody titre was very high and subsequently fêl significantly.

We have described a patient with clinical an laboratory evidence of subacute thyroiditis. We sug gest that the thyroiditis was an extrapulmonary mand festation of psittacosis, since the patient hat serological evidence of chlamydial infection which wie believe to be $C$. psittaci. As the causal agent $\overrightarrow{d t}$ subacute thyroiditis is infrequently identified and the true incidence of psittacosis is probably undere timated (Editorial, 1984), chlamydial infections of the gland may be more common than has been previousfy thought. This case also illustrates the symptomatis response to thyroxine which occurs in $65 \%$ of patients with subacute thyroiditis (Greene, 1971), and the frequent absence of reported contact with birds in patients with psittacosis (Macfarlane \& Macrae, 1983).

MACFARLANE, J.T. \& MACRAE, A.D. (1983). Psittacasis. British Medical Bulletin, 39, 163.

MURRAY, H.W.\& TUAZON, C. (1980). Atypical pneumon̆tas Medical Clinics of North America, 64, 507.

SEIBERT, R.H., JORDAN, W.S. \& DINGLE, J.H. (195ळ Clinical variations in the diagnosis of psittacosis. Ne England Journal of Medicine, 254, 925. 